\title{
El traductor es un trabajador como otro cualquiera..., y es muy importante que no esté solo
}

\section{The translator is a worker like any other..., and it is very important that he or she should never work alone}

\section{María Teresa Gallego URRUtia}

Traductora autónoma, ACE Traductores

mtgu@acett.org

\section{INTRODUCCIÓN}

María Teresa Gallego Urrutia nació en Madrid en el año 1943. Realizó sus estudios en el Liceo francés de Madrid y fue allí donde se licenció en Filología Moderna Francesa años más tarde por la Universidad Complutense. Su andadura por la traducción literaria comenzó en 1961 y, desde entonces y hasta el momento, ha traducido alrededor de 200 obras de los autores franceses y francófonos más destacados. Encontramos entre ellos a Albert Camus, Honoré de Balzac, Víctor Hugo o Marcel Proust. En el año 1974, obtuvo la cátedra de francés del Instituto Gregorio Marañón de Madrid. Por su trayectoria como traductora ha recibido numerosos reconocimientos, entre los que podemos nombrar el Premio Nacional de Traducción de Lenguas Románicas por El diario de un ladrón de Jean Genet en 1977 y el premio Stendhal por Impresiones de África de Raymond Roussel, ambos compartidos con Isabel Reverte Cejudo. Además ha recibido la condecoración Ordre des Arts et des Lettres por el Gobierno francés en el año 
2003 y, cinco años más tarde, recibió el Premio Nacional a la obra de un traductor. En el año 2011 recibió el premio Mots Passants que concede el Departamento de francés de la Universidad Autónoma de Barcelona por su traducción de El horizonte de Patrick Modiano. Finalmente, en 2003 recibió el premio Esther Benítez por su traducción de La señora Bovary de Gustave Flaubert.

Aunque dio sus primeros pasos en el mundo de la traducción jurídica, María Teresa Gallego Urrutia es una traductora literaria de referencia que nunca ha descuidado su faceta docente. Desde 2008 hasta 2013, impartió clases sobre derecho de propiedad intelectual del traductor en el Instituto de traductores de la Universidad Complutense de Madrid. Colabora activamente con publicaciones como el Trujamán, del Instituto Cervantes, la revista Turia y Letra Internacional, entre otros.

Palabras clave: traducción; traducción literaria.

\section{ENTREVISTA}

Fecha: 10/19/2017

Manuel de la Cruz: Muy buenos días. ¿Qué tal estás?

MTGU: Aquí estoy esperando vuestras preguntas.

Esther Ugarte: Bueno, lo primero que nos gustaría saber es cómo empezaste en la traducción editorial, más concretamente, en la traducción literaria.

MTGU: Sí, la traducción literaria porque habéis nombrado a la etapa de traductora jurídica, que es cierta, pero que fue hace ya muchísimos años. Es más, fue mi primer trabajo cuando acabé la carrera. De eso hace ya... Ni se sabe el tiempo que hace ya de eso.

Empecé, vamos a ver, ¿podemos llamarlo por un poco de cara dura? Pues a lo mejor, no lo sé. Empecé porque cuando yo estaba a punto de empezar Filología Francesa en la Complutense, tenía clarísimo que quería ser... bueno, quería ser todo, pero entre otras cosas quería ser traductora editorial, de literatura, perdón, no editorial porque todavía eso era un concepto que no estaba tan definido como ahora, pero sí traductora de literatura francesa. Bien, quizá muchas cosas de las que quería ser no estaban a mi alcance, pero esa pensaba yo que sí podría estarlo. Entonces se me ocurrió, con la insensatez de los 18 años, en que no dudas de nada y te estás comiendo la vida, pues pensé que si escribía a un director de una editorial y le decía que quería ser traductora y que si quería tenerme en cuenta, pues que a ver qué pasaba. Entonces, ni corta ni perezosa, agarré una hoja y un bolígrafo porque todavía lo del ordenador no existía y todavía no había aprendido a escribir a máquina en aquel momento, así que agarré un bolígrafo y un folio y escribí al director de Seix Barral, porque era una editorial

María Teresa GALLEGo URRUTIA El traductor es un trabajador como otro cualquiera..., y es muy importante que no esté solo
CLINA

vol. 7-1, June 2021, 103-110

elSSN: 2444-1961

Ediciones Universidad de Salamanca - CC BY-NC-ND 
que conocía y conocía el nombre del director. Pensé en Seix Barral porque sabía a quién dirigirme, digamos. Escribí a Joan Petit y le conté un poco mi vida. «Pues soy estudiante, voy a empezar filología francesa, soy una gran lectora, quiero ser traductora literaria, etc». La mandé y resulta que el señor Petit me llamó por teléfono al poco tiempo, y yo me quedé, bueno, encantada de la vida y también un poco asombrada de que esa gestión alocada hubiera dado resultado. Hablamos unos momentos y me dijo «Pues mira, hazme una prueba» y me encargó que hiciera una prueba de unos capítulos de un libro súper enrevesadísimo, que es un libro del Nouveau Roman, aquella corriente que estaba entonces en boga. Era un libro que se llamaba El viento y que creo que incluso ahora traduciría con dificultad. Le hice la prueba, que debió de ser una cosa totalmente espantosa, pero me volvió a llamar y me dijo «Mira, la traducción es muy mala, efectivamente, pero yo veo aquí madera de traductor en esta prueba tan mala y llena de errores y de tanteos. Te voy a dar un libro». Y no me dio cualquier libro, es que me dio el Goncourt de ese año, que lo había ganado Jean Cau, que era secretario de Sartre en aquel momento. Bueno, ipues así empecé! El señor Petit tuvo el enorme detalle de darme un libro y no solamente darme un libro, sino que además me dijo «mándame un borrador y lo vamos mirando los dos juntos por teléfono» porque él estaba en Barcelona y yo, en Madrid. Capítulo del que le mandaba un borrador, capítulo que él me llamaba por teléfono y me decía «mira esto, aquí hay un acierto, pero deberías profundizar más por aquí. Aquí, en cambio, pues este tiempo verbal no es el más adecuado». Y así hice el libro, así lo pasé a limpio y luego no se publicó porque lo prohibió la censura española, y se publicó luego más adelante en México. La persona por la que soy traductora fue Joan Petit, que me dio una traducción y que además fue mi mentor, el que me ayudó, me empezó a enseñar el oficio. Y resulta que a partir de ahí ya empezaron a llegar más traducciones y hasta hoy. O sea, empecé con un atrevimiento juvenil.

Ana Fernández: Pues muy interesante. Bueno, también tengo entendido que formó parte del grupo que fundó ACE Traductores y queríamos preguntarle también por qué cree que es tan importante que los traductores nos asociemos o que existan este tipo de asociaciones.

MTGU: Por diferentes motivos. El primer motivo es que el traductor, el trabajador, porque siempre hablo de trabajadores cuando hablo de traductores, tiene que estar en contacto con sus compañeros. Esencialmente porque es una forma de resistencia o de lucha por los derechos y de resistencia ante alguna explotación. Y no es solamente cosa de los traductores, sino de cualquier trabajador. Por eso hay sindicatos.

Los trabajadores tienen que estar unidos, defender su profesión, defender su trabajo, sus emolumentos, lógicamente, sus condiciones de trabajo y eso no lo pueden hacer de uno en uno, tienen que hacerlo juntos. El traductor es un trabajador como otro cualquiera y si por condiciones específicas en vez de trabajar en una fábrica o en una oficina en la cual se ve todo el día con sus compañeros, trabaja en casa, es un

María Teresa GALLEGo URRUTIA El traductor es un trabajador como otro cualquiera..., y es muy importante que no esté solo
CLINA

vol. 7-1, June 2021, 103-110

elSSN: 2444-1961

Ediciones Universidad de Salamanca - CC BY-NC-ND 
trabajo que se hace en solitario, y es muy importante que no esté solo, sino que remedie esa soledad cotidiana con un contacto lo más frecuente posible con los demás colegas que trabajan, para una defensa de la profesión y de los derechos de los trabajadores. Eso, por una parte, que para mí es la esencial. Por otra parte, también por la ayuda que nos prestamos. En un trabajo tan creativo como es la traducción siempre tienes que preguntar a algún colega, que plantearle dudas: «Me ha salido esto, ¿vosotros qué opináis? ¿Os parece que esto, según lo digo así, va a quedar claro? ¿Me podéis aconsejar si puedo leer algún texto sobre tal o cual escritor que estoy traduciendo y quería saber algo más?». La ayuda mutua en el terreno del trabajo, en el terreno de la creación, es muy importante para el traductor y por eso tanto laboralmente como intelectualmente estar incluido en un grupo, en un colectivo, como se dice ahora, me parece indispensable.

MDLC: Y, además, quería decir que hace unos días se presentó la campaña del Día de la Traducción y se hablaba sobre esa invisibilidad del traductor que trabaja desde su casa y al que normalmente no se le reconoce esa labor de autor, digámoslo así.

MTGU: No, bueno, eso es otra cosa. Es otro tema en el cual también las asociaciones pueden hacer, y ya han hecho, muchas cosas. ACE traductores, entre otras cosas, - por supuesto, no fue ella sola la que pudo hacerlo - en el año 1987, junto con otras asociaciones que agrupaban a creadores con derechos de propiedad intelectual, consiguió una nueva Ley Propiedad Intelectual, cumple ahora mismo precisamente 30 años. Echo mucho de menos que no se esté conmemorando el aniversario de esta ley, que fue la que reconoció al traductor como autor de sus traducciones, porque hasta ese momento al traductor le encargaban una traducción, le pagaban una cantidad y luego la editorial podía hacer lo que quisiera con ella. Podía publicarla, dejar de publicarla, podía enmendarla... Podía hacer lo que le pareciera bien sin darle cuentas a nadie. Éramos conscientes de ello desde hacía mucho y la primera asociación de traductores que hubo en España, que se llamaba APETI y a la cual pertenecí antes de que se fundara lo que es hoy ACE Traductores, empezó con esta lucha, ACE Traductores la siguió, no ella sola, por supuesto, y se consiguió que se redactara y que se aprobara la actual Ley de Propiedad Intelectual, que es la que nos ha reconocido como autores. La ley nos llama «autores de obra derivada» porque la obra evidentemente no es nuestra, lo que nuestro es la derivación, la reescritura de esa obra en otro idioma. De todas formas, yo debo decir que me parece que se incide demasiado, y que eso es malo, en el tópico del traductor invisible. No es cierto. En este momento el traductor no es invisible, tiene su nombre en la portadilla de todas sus traducciones, el traductor tiene unos contratos que le reconocen su derecho en calidad de autor y el traductor tiene, sobre todo en este momento con el auge de internet, una presencia porque interviene en entrevistas, porque puede poner comentarios al pie de algún artículo de la versión digital de un diario; en cuanto una reseña de algún periódico que leo no menciona al traductor de una obra a la que se está refiriendo pongo un comentario a pie de artículo

María Teresa GaLLEGo URRUTIA El traductor es un trabajador como otro cualquiera..., y es muy importante que no esté solo
CLINA

vol. 7-1, June 2021, 103-110

elSSN: 2444-1961

Ediciones Universidad de Salamanca - CC BY-NC-ND 
para reivindicar nuestra labor en la difusión de la literatura. Tenemos un trabajo con dificultades como todo trabajador, todo trabajo tiene problemas y hay que luchar por solucionarlos, pero no puedes estar todo el día gimoteando. Lo que hay que hacer es remediar esa situación, pero no estar todo el día : «Ay, Dios mío, que somos invisibles y nos pagan mal». Pues sí, somos invisibles y nos pagan mal dentro de un orden. Esta condición la compartimos con miles de trabajadores de otras profesiones. Hay que hablar de otras cosas, no estar todo el día convenciendo a la gente de que somos pobres e invisibles. Primero porque no es del todo cierto; lo de que la mayoría de las tarifas no son altas y que cuesta vivir de ellas, eso sí es cierto. Pero es que salarios insuficientes tienen en este momento en España miles de millones de trabajadores. Hacer hincapié sólo en eso cuando hablamos de nosotros, a mí me parece que es perjudicial, que es una especie de imagen victimista y que, al contrario, lo que hay que hacer es remediar eso, no estar todo el día quejándose.

AF: Totalmente de acuerdo, María Teresa. Volviendo al tema de las condiciones de trabajo, antes nos hablabas de que durante tu primera traducción, capítulo a capítulo ibas hablando con Joan Petit sobre cambios que se hacían en la novela que tú traducías. Nos gustaría saber a todos cómo has sido testigo tú de la evolución de las condiciones de trabajo de los traductores literarios.

MTGU: Al contrario, lo de Seix Barral fue una enorme consideración de esa editorial y de su director en aquel momento con traductor, porque no solamente fue lo bastante, no quiero decir «bondadoso», me parece una palabra muy blandurria, pero sí lo bastante... No encuentro la palabra para definir lo que hizo Petit, pero el caso es que fue formando a una nueva traductora sin que nadie se lo pidiese, sin obligación ninguna. Por otra parte, la editorial era realmente respetuosa con los derechos del traductor.

MDLC: ¿Cómo ha ido evolucionando?

MTGU: Esa fue una historia que me pasó a mí, pero todo ha ido evolucionando, claro. En cuanto a la pregunta... Se me ha olvidado la pregunta, repítemela, por favor.

AF: Sí, claro, María Teresa. En cuanto a las condiciones de trabajo, ¿cómo has visto tú que han ido evolucionando, sobre todo con respecto a las nuevas tecnologías?

MTGU: ¿Qué pasaba cuando yo empecé? Cuando yo empecé me uní a la asociación APETI a los 17 años, y luego fundamos ACE Traductores. En aquel momento, como ya he dicho, el traductor recibía un encargo de una editorial y se pactaba un precio. Bueno, se «pactaba», más bien te lo decían ellos. «Te podemos pagar tanto, te vamos a pagar tanto por tal traducción». Había editoriales - ahora hay muchas menos, son relativamente pocas - donde no hacían un contrato, pero la mayor parte hacían un contrato ya. Ese contrato, lo que pasa es que era lo que era: se ajustaba a la Ley de

María Teresa GALLEGo URRUTIA El traductor es un trabajador como otro cualquiera..., y es muy importante que no esté solo
CLINA

vol. 7-1, June 2021, 103-110

elSSN: 2444-1961

Ediciones Universidad de Salamanca - CC BY-NC-ND 
Propiedad Intelectual que había entonces, una ley de finales del XIX, no lo pierdas de vista. La Ley de Propiedad Intelectual con la que trabajamos hasta el año 1987 era una ley de finales del siglo XIX, que estaba además orientada esencialmente al escritor, no al traductor. El traductor ni se contemplaba entre otras cosas porque, en el siglo XIX, el traductor no era un trabajador, solía ser algún escritor, un intelectual de reconocido prestigio que además traducía digamos que por su propia gloria y por amor al arte, a la literatura; traducía grandes obras normalmente, grandes clásicos. Y también se fueron traduciendo otro tipo de cosas, pero no era una profesión como lo fue luego, no había unos profesionales que vivieran de eso. Esa ley estaba totalmente desfasada; lo que sí había ocurrido cuando yo empecé era que había un contrato muy breve, que solía ser de media página, en el cual te decía la editorial que te encargaba tal cosa, que había que entregarla en tal fecha y que te pagaba tanto. Tú firmabas el contrato, traducías el libro, lo entregabas en la fecha prevista, te pagaban la cantidad que había fijado la editorial y ya está. La editorial publicaba el libro, lo reeditaba las veces que fuera o decidía no editarlo más si el libro no tenía mucha salida. A veces hacía cambios, había muchos cortes. No hay que olvidar que vivíamos en el franquismo. Bueno en 1987 ya no, pero hasta 1975 había censura porque vivíamos en el franquismo. Esa censura muchas veces suprimía cosas, le parecía que algo iba en contra de la religión o de las buenas costumbres y decía a la editorial «señores, este libro no se aprueba». Todo libro tenía que pasar por una censura previamente, no se editaba libro durante el franquismo que no pasara por la censura. Y la censura muchas veces hacía cortes, suprimía cosas. A ti ni te informaban, la editorial peleaba con la censura y como la traducción era de la editorial, nadie te decía nada. Cuando se publicaba el libro, cogías un ejemplar y lo hojeabas y decías «ah, si falta esto. Anda, jis esto lo han quitado!». Te enterabas en ese momento. Era como si fueras modista e hicieras un vestido, se lo dieras a la persona que te ha encargado el vestido y luego esa persona era dueña del vestido y lo alargase, lo metiese, lo estrecharse, lo llevase al tinte o lo tirarse a la basura. La traducción no era nuestra. Claro, el gran progreso de 1987 fue que la traducción era nuestra. La editorial no te puede decir «te cambio esto, te quito lo otro». No, te manda las galeradas y tú apruebas o rechazas las sugerencias que hace un corrector o un revisor. La traducción es tuya a todos los efectos.

MDLC: Sí. Ya sabes que el tiempo en la radio corre rapidísimo.

MTGU: Yo creo que demasiado.

MDLC: Vamos a ir ya terminando. Estamos en nuestros últimos minutos, tiene que ser muy breve, pero nos gustaría que dieras un mensaje a las nuevas traductoras y traductores que van a salir de nuestras facultades. $O$, simplemente, que no salgan de las facultades que se dediquen a esto.

María Teresa Gallego URRUTIA El traductor es un trabajador como otro cualquiera..., y es muy importante que no esté solo
CLINA

vol. 7-1, June 2021, 103-110

elSSN: 2444-1961

Ediciones Universidad de Salamanca - CC BY-NC-ND 
MTGU: Consejos, lo más rápidamente que pueda. Primero, que sean extremadamente cultos, que lean continuamente, que sean enciclopedistas, que sean humanistas, que sepan de todo, que tengan curiosidad por investigar, que investiguen, que dominen la lengua perfectamente. Por otra parte, que sean trabajadores, que se asocien, que trabajen todos juntos, que sean solidarios y que luchen por unos derechos.

MDLC: Muchísimas gracias, María Teresa Gallego Urrutia. Ha sido todo un placer tenerte aquí.

MTGU: Ya sé que hablo demasiado y muy deprisa, lo siento.

MDLC: Pero es estupendo, porque nos da tiempo a meterlo todo, todo, todo en 20 minutos.

MTGU: Bueno, pues ya está. Nos vemos este miércoles.

MDLC: Sí y te agradecemos muchísimo que hayas aceptado nuestra invitación.

MTGU: ¡Por favor! Si esto para mí es... Que me pregunte cosas la gente joven me parece un privilegio y un honor, qué quieres que te diga. Me siento muy agradecida.

MDLC: Muchas gracias y también gracias en el nombre de nuestra Facultad. Te damos las gracias de que vengas a inaugurar nuestro curso académico, que también es para nosotros un privilegio...

\author{
Entrevista: «Ana Fernández, Esther Ugarte, Manuel de la Cruz» \\ Transcripción: Beatriz Guerrero García \\ Enlace: https://programadondelenguas.blogspot.com/2017/10/entrevista-maria-teresa-gallego-urrutia.html \\ Duración: 24:38:00
}

\title{
NOTA BIOGRÁFICA
}

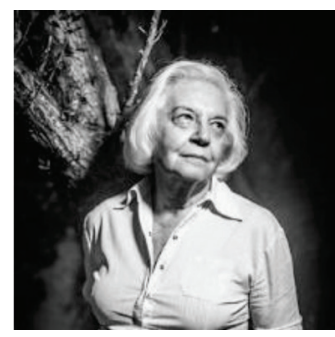

María Teresa Gallego Urrutia. Traductora literaria. Ex-Presidenta de Acett. Traduce del francés. Su andadura por la traducción literaria comenzó en 1961 y desde entonces y hasta el momento, ha traducido alrededor de 200 obras de los autores franceses y francófonos más destacados. De hecho, es suya la que es considerada la mejor traducción de Los miserables de Víctor Hugo.

María Teresa GaLLEGo URRUTIA El traductor es un trabajador como otro cualquiera..., y es muy importante que no esté solo 
En el año 1974 obtuvo la cátedra de Francés del Instituto Gregorio Marañón de Madrid. Por su trayectoria como traductora ha recibido numerosos reconocimientos, entre los que podríamos destacar el Premio Nacional de Traducción de Lenguas románicas por Diario del ladrón de Jean Genet (1977) y el Premio Stendhal por Impresiones de África de Raymond Roussel (1991), ambos compartidos con Isabel Reverte Cejudo.

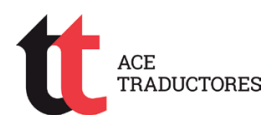

María Teresa Gallego Urrutia:

https://ace-traductores.org/asociados/ver-asociado/?d=mariateresa-gallego-urrutia

\section{TRADUCCIONES DESTACADAS}

Bitna bajo el cielo de Seúl, de Le Clézio, J.M.G. Narrativa - Lumen, 2019. Traducción.

La cartuja de Parma, de Stendhal. Narrativa - Alba Editorial, 2019. Traducción.

De los libros, de Michel de Montaigne. Ensayo - Nórdica, 2019. Traducción.

Los caballos de Dios, de Mahi Binebine. Narrativa - Alfaguara, 2018. Traducción. 